\title{
Lasers in the Conservation of Artworks
}

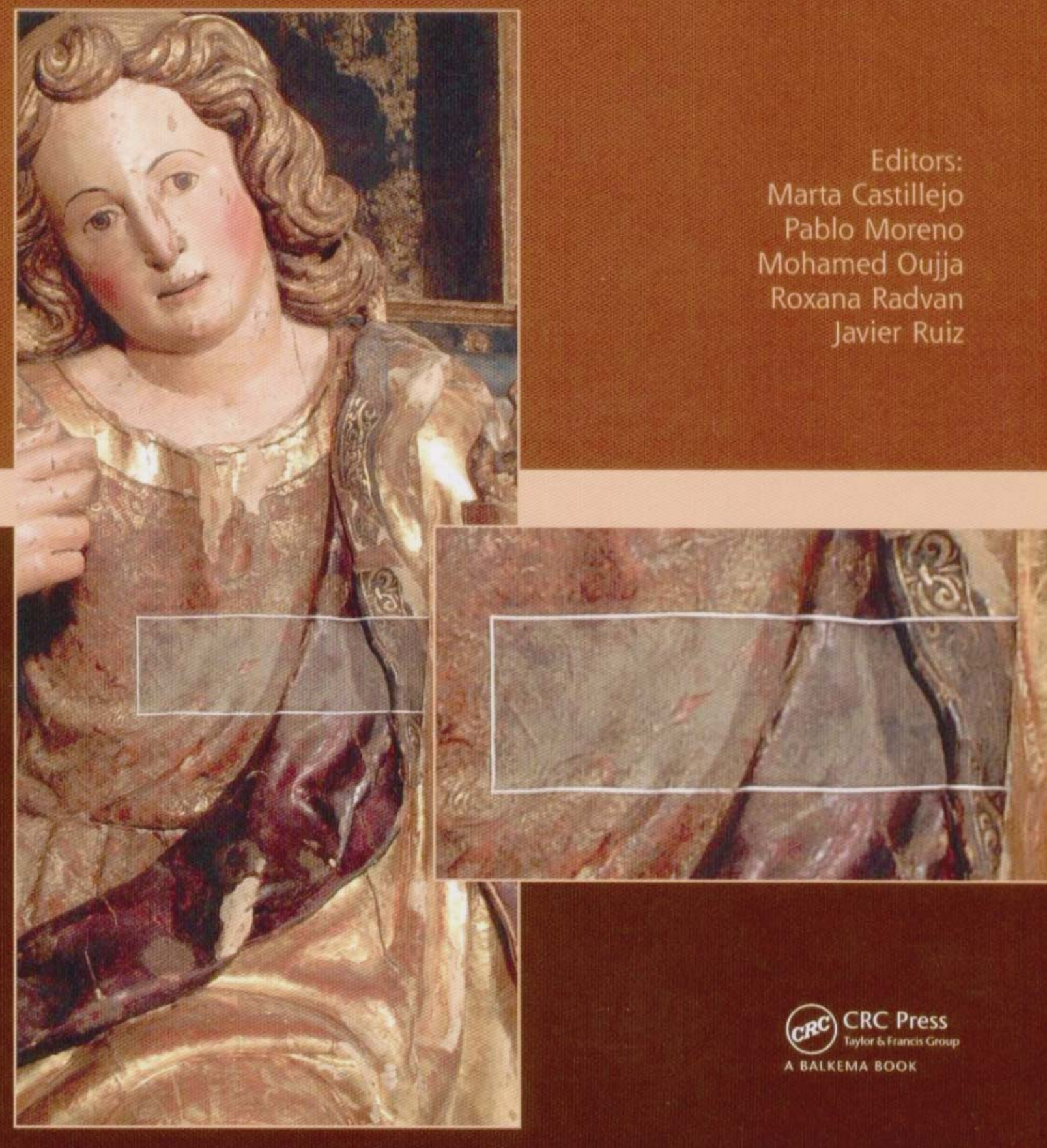


CRC Press/Balkema is an imprint of the Taylor \& Francis Group, an informa business

C 2008 Taylor \& Francis Group, London, UK

Typeset by Charon Tec Ltd (A Macmillan Company), Chennai, India Printed and bound in Great Britain by Cromwell Press Ltd, Towbridge, Wiltshire

All rights reserved. No part of this publication or the information contained herein may be reproduced, stored in a retrieval system, or transmitted in any form or by any means, electronic, mechanical, by photocopying, recording or otherwise, without written prior permission from the publishers.

Although all care is taken to ensure integrity and the quality of this publication and the information herein, no responsibility is assumed by the publishers nor the author for any damage to the property or persons as a result of operation or use of this publication and/or the information contained herein.

Published by: CRC Press/Balkema

P.O. Box 447, 2300 AK Leiden, The Netherlands

e-mail: Pub.NL@taylorandfrancis.com

www.crcpress.com - www.taylorandfrancis.co.uk - www.balkema.nl

ISBN 13: $978-0-415-47596-9$ 


\title{
Study of chromophores of Islamic glasses from Al-Andalus (Murcia, Spain)
}

\author{
N. Carmona, M. Garcia-Heras \& M.A. Villegas \\ Instituto de Historia, Centro de Ciencias Humanas y Sociales, CCHS-CSIC, and Centro \\ Nacional de Investigaciones Metalúrgicas, CENIM-CSIC, Madrid, Spain \\ P. Jiménez \& J. Navarro \\ Escuela de Estudios Arabes, EEA-CSTC, Granada, Spain
}

ABSTRACT: The recent discovery and excavation of 12th century AD urban glass workshops in the city of Murcia (Spain) have provided good evidences of glass production in the ancient Islamic territory of Al-Andalus. Among other findings, an important amount of bulk coloured and colourless glass fragments were unearthed during the archaeological works undertaken. This research presents the results obtained in the characterization of the chromophores responsible of the different colours found in the glass ensemble, namely turquoise blue, green bluish, emerald green, purple, yellow and red. The main goal of the study was to get some insights into the technology developed to obtain different colours in glasses. The resulting data have allowed the assignment of the ions responsible for each colour studied and have provided outstanding information on the colouring techniques used by the Islamic glassmakers of Al-Andalus.

\section{INTRODUCTION}

Up to now, little was known on technological aspects of Islamic glasses manufactured in the ancient territory of Al-Andalus (Southern Spain, AD 711-1492). However, the recent discovery and systematic archaeological excavation of urban glass workshops in the city of Murcia has changed this situation since, for the first time, it is possible to have glasses related to production sites with a chronology of mostly the 12 th century AD (Jiménez Castillo et al. 2000). These workshops are the first evidence of glass production in the region of Murcia and are currently the only well documented in Al-Andalus, except the workshop of Pechina (Castillo \& Martínez 2000).

Throughout the 12 th century and, particularly, during the kingdom of Ibn Mardanish, Murcia reached a high splendour to such as extent that it was one of the most prominent west Mediterranean cities of that time. For this reason, some Arab written sources reported that Murcia was an important glass production centre (e.g., De Gayangos 1984, Jiménez Castillo 2000). Ibn Mardanish fought against the Almohads, who came from north of Africa and rapidly dominated the most part of $\mathrm{Al}$-Andalus, during more than two decades until the city fell in AD 1172 (Jiménez Castillo 2003). The location of Murcia and the approximate boundary between the Christian and Islamic territories

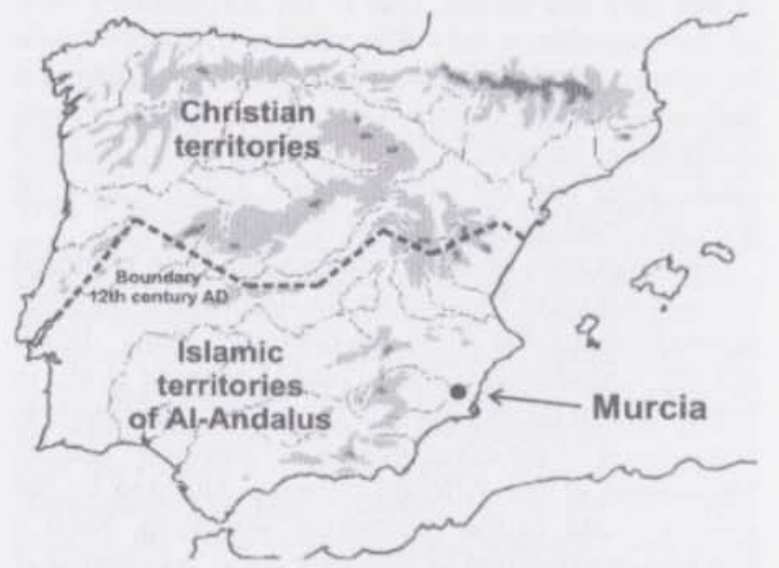

Figure 1. Map of the Iberian Peninsula showing the location of Murcia and the approximate boundary between the Christian and the Islamic territories around the 12 th century AD.

of Al-Andalus around the 12th century $\mathrm{AD}$ are shown in Figure 1.

One of these Murcian workshops is located in the Puxmarina street. The archaeological excavation of this site revealed a total of five well preserved furnaces and some remains of three others. These furnaces have been dated by archeomagnetism between AD 1100 and 

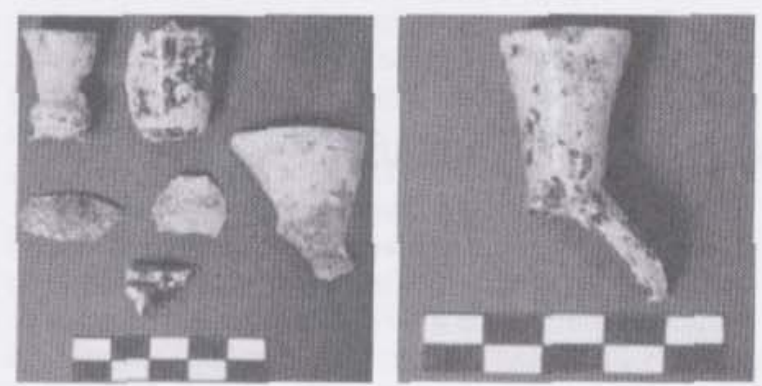

Figure 2. Some of the glass fragments from the Puxmarina workshop (Murcia, Spain) in the state as-received in the laboratory. Scales are in $\mathrm{cm}$.

1200 (Gómez-Paccard et al. 2006). Contextual information suggested that at least three of the furnaces could have been used for glass melting. The excavation also provided a very fragmented ensemble of glasses, together with some glassworking waste evidences such as glass dribbles and threads, melts from batches and crucible remains (Jiménez Castillo et al. 2005). The main glass forming technique was blowing, even though some flat glass fragments were also present. The majority of glasses were colourless or slightly yellowish and, less frequently, turquoise blue, green bluish and purple. Only a few fragments of emerald green, yellow and red glasses were documented. All of them were transparent and bulk coloured in those cases in which they had colour. Due to the fragmentary state of the ensemble, a very few number of shapes could be reconstructed, including small vases or unguentaria and small necked bottles. Decoration is only present in a reduced number of fragments and is composed of black, white and red paints. Figure 2 shows some of the glass fragments recovered in the excavation.

The relevance of such findings has been explored through a project focused on the archaeometric characterization of the glass productions, using different physical-chemical techniques (Carmona et al., in press). One of the key goals of the project was the characterization of the chromophores or chemical species responsible of the different colours exhibited by the glasses found in the Puxmarina workshop. Such a research is presented in this paper and was aimed at providing some insights into the technology developed by the glassmakers of Mureia, in order to shed new light on the general topic of the Islamic glass technology of Al-Andalus.

\section{EXPERIMENTAL}

\subsection{Samples selected}

In the first place, a total of 21 fragments, including glasses and remains of melt batches from furnaces, were selected to determine the chemical composition of the glass ensemble. This selection encompassed the whole range of colours. In the second place, a sample of turquoise blue, green bluish, emerald green, purple, yellow and red glasses were taken to characterize their corresponding chromophores. In both cases, those fragments without a recognizable typological form were preferentially selected to undertake destructive analyses.

\subsection{Analytical techniques}

Chemical analyses were carried out by X-ray Fluorescence (XRF) using a Philips PW-1404 wavelength dispersed X-ray spectrometer equipped with a tube of rhodium. Analytical determinations were obtained through the standard-less analytical software Uniquant 4.22 based on fundamental parameters. Once external deposits were removed by polishing to avoid contaminations, powder samples were prepared by grinding body glass fragments in an agate mortat Then, pressed boric acid pellets, using a mixture of n-butylmethacrylate and acetone $(10: 90 \mathrm{wt} \%$ ) as bonding medium, were made for the XRF analyses.

The characterization of the glass chromophores was undertaken by UV/VIS absorption spectrophotometry using a Shimadzu 3100 spectrophotometer attached with an integrating sphere. Spectra were acquired in the $380-800 \mathrm{~nm}$ range on transparent glass samples of approximately $1 \mathrm{~mm}$ in thickness. The samples were obtained by polishing both sides of the glasses with a manual rotating polisher using an aqueous suspension of cerium oxide to remove external deposits. To the best of the authors' knowledge UV/VIS absorption spectrophotometry has been little used in archaeolog. ical glasses despite its advantages to investigate then colours and chromophores (Sanderson \& Hutchings 1987, Garcia-Heras \& Villegas 2004)

\section{RESULTS AND DISCUSSION}

\subsection{Chemical analysis}

According to the chemical data obtained by XRF, the glasses studied can be classified into two distinct groups: 1) soda-lime-silicate glasses [ $\mathrm{Na}_{2} \mathrm{O}-\mathrm{CaO}$. $\left.\mathrm{SiO}_{2}\right]$ and 2) soda-lime lead-silicate glasses $\left[\mathrm{Na}_{2} \mathrm{O}\right.$. $\mathrm{CaO}-\mathrm{PbO}-\mathrm{SiO}_{2}$ ], which are characterized by a high content of lead oxide. All the colourless and most of the bulk coloured glasses belong to the first group, whereas the second one is only represented by emerald green glasses. Mean and standard deviation of the 13 main components of both groups are displayed in Table 1 .

The major component of soda-lime-silicate glasses is the network-former $\mathrm{SiO}_{2}(58.83 \mathrm{wt} \%)$. The glas network-modifier $\mathrm{Na}_{2} \mathrm{O}$ shows a relatively high concentration $(19.28 \mathrm{wt} \%$ ), while the content of the 
Table 1. Results derived from the XRF chemical analysis of glasses (weight \%).

\begin{tabular}{|c|c|c|c|c|}
\hline & \multicolumn{2}{|c|}{$\begin{array}{l}\text { Soda-lime-silicate } \\
(\mathrm{n}=419)\end{array}$} & \multicolumn{2}{|c|}{$\begin{array}{l}\text { Soda-lime lead-silicate } \\
(\mathrm{n}=2)\end{array}$} \\
\hline & Mean & S.D. & Mean & S.D. \\
\hline $\mathrm{Na}_{2} \mathrm{O}$ & 19.28 & 1.88 & 12.46 & 3.10 \\
\hline $\mathrm{MgO}$ & 4.89 & 0.89 & 2.61 & 0.69 \\
\hline $\mathrm{Al}_{2} \mathrm{O}_{3}$ & 3.77 & 1.47 & 3.00 & 1.51 \\
\hline $\mathrm{SiO}_{2}$ & 58.83 & 2.64 & 49.77 & 3.68 \\
\hline $\mathrm{P}_{2} \mathrm{O}_{5}$ & 0.27 & 0.06 & 0.12 & 0.02 \\
\hline $\mathrm{SO}_{2}$ & 0.15 & 0.04 & 0.16 & 0.04 \\
\hline $\mathrm{Cl}^{-}$ & 1.06 & 0.17 & 0.84 & 0.08 \\
\hline $\mathrm{K}_{2} \mathrm{O}$ & 2.16 & 0.48 & 1.52 & 0.50 \\
\hline $\mathrm{CaO}$ & 7.27 & 0.98 & 4.92 & 0.14 \\
\hline $\mathrm{TiO}_{2}$ & 0.19 & 0.08 & 0.14 & 0.03 \\
\hline $\mathrm{MnO}$ & 0.34 & 0.26 & 0.10 & 0.04 \\
\hline $\mathrm{Fe}_{2} \mathrm{O}_{3}$ & 0.96 & 0.22 & 1.39 & 1.29 \\
\hline $\mathrm{PbO}$ & 0.83 & 1.35 & 22.97 & 7.79 \\
\hline Total & 100.00 & & 100.00 & \\
\hline
\end{tabular}

S.D. Standard deviation $( \pm)$.

network-stabilizer $\mathrm{CaO}$ is $7.27 \mathrm{wt} \%$. The amounts of other network-modifiers such as $\mathrm{MgO}$ and $\mathrm{K}_{2} \mathrm{O}$ are 4.89 and $2.16 \mathrm{wt} \%$, respectively. The content of $\mathrm{Al}_{2} \mathrm{O}_{3}$, which is also a network-former oxide, is $3.77 \mathrm{wt} \%$. The percentages of $\mathrm{P}_{2} \mathrm{O}_{5}$ and $\mathrm{SO}_{2}$ are not higher than $0.30 \mathrm{wt} \%$ and chloride ions range around $1 \mathrm{wt} \%$. Minor components determined were transition metals such as $\mathrm{TiO}_{2}(0.19 \mathrm{wt} \%), \mathrm{MnO}(0.34 \mathrm{wt} \%)$ and $\mathrm{Fe}_{2} \mathrm{O}_{3}$ $(0.96 \mathrm{wt} \%)$. Iron and titanium oxides can be considered as impurities of the raw materials. However, the manganese oxide was intentionally added as a chromophore to provide the purple colour as is discussed in the next section.

This first group of glasses can be classified as high magnesia plant ash glasses (HMG) according to the terminology proposed by Sayre \& Smith (1961). The use of plant ashes as a source of sodium oxide is documented throughout the Islamic world between the nine and fifteenth centuries $\mathrm{AD}$ and is strongly indicated by the high contents of $\mathrm{Na}_{2} \mathrm{O}$ and $\mathrm{MgO}$, as well as the noticeable concentration of $\mathrm{K}_{2} \mathrm{O}$ (Tab. 1). These indicators suggest that natron was not used as alkali source because the concentrations of $\mathrm{MgO}$ and $\mathrm{K}_{2} \mathrm{O}$ had to be then lower or around $1,00 \mathrm{wt} \%$.

In the second group, that of soda-lime leadsilicate glasses, the major component is also $\mathrm{SiO}_{2}$ $(49.77 \mathrm{wt} \%$ ). In this group the content of $\mathrm{PbO}$ is around $23.00 \mathrm{wt} \%$, which at high concentrations can play the role of a network-former oxide (Götz et al. 1976, Fernández Navarro 2003). The percentage of $\mathrm{Na}_{2} \mathrm{O}$ is $12.46 \mathrm{wt} \%$, that of $\mathrm{CaO}$ is around $5.00 \mathrm{wt} \%$ and the content of $\mathrm{K}_{2} \mathrm{O}$ is $1.52 \mathrm{wt} \%$. On the other hand, the concentration of $\mathrm{MgO}$ is a little bit lower

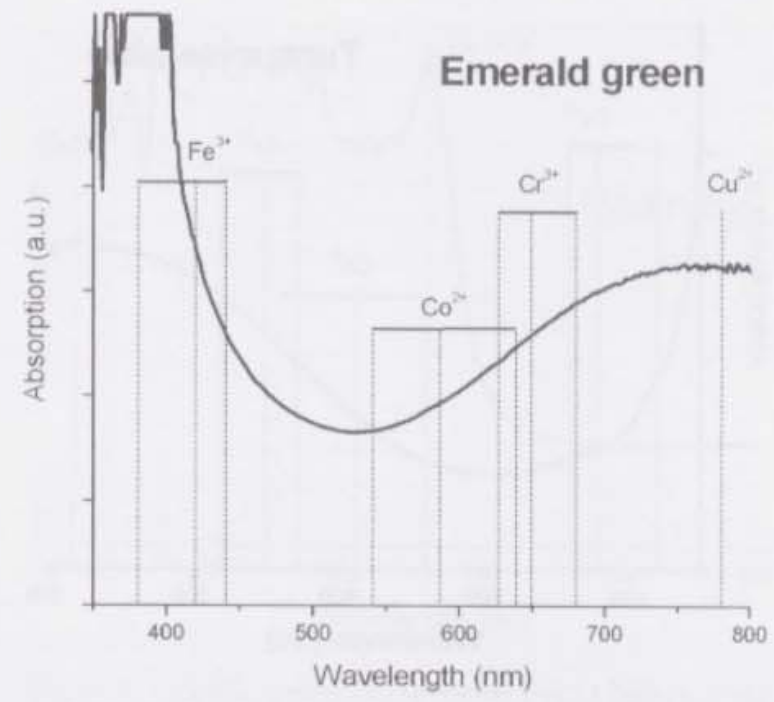

Figure 3 . Visible absorption spectrum from a bulk emerald green soda-lime lead-silicate glass.

( $2.61 \mathrm{wt} \%$ ) than in the first group of glasses. The rest of components are otherwise very similar in both groups.

Soda-lime lead-silicate glasses can be classified as Islamic high lead oxide glasses, following the terminology of Sayre \& Smith (1961), and are documented in the same period of time.

\subsection{Characterization of chromophores}

Figure 3 shows the absorption spectrum from a bulk emerald green glass. According to chemical analysis data, it seems that this colour was only produced in soda-lime lead-silicate glasses. The sample presents a unique wide absorption band of high intensity which can be assigned to $\mathrm{Cu}^{2+}$ ions. The band shifts towards lower wavelengths up to $740 \mathrm{~nm}$. This can be attributed to the incorporation of high contents of lead oxide to the glass network since, as mentioned above, it can play the role of a network-former oxide at high concentrations. The high polarisability of the $\mathrm{Pb}^{2+}$ ions induces the glass to asymmetric structures able to be deformed (Fernández Navarro 2003: 453). This fact shifts the absorption band of $\mathrm{Cu}^{2+}$ ions from $\sim 800$ to $\sim 740 \mathrm{~nm}$, thereby changing the colour from blue to emerald green. The presence of copper oxide in this glass $(4.22 \mathrm{wt} \%)$ was confirmed by chemical analysis data obtained by XRF. The UV absorption edge of this sample is around $425 \mathrm{~nm}$ and is probably due to the presence of $\mathrm{Fe}^{3+}$ ions which absorb at 380,420 and $440 \mathrm{~nm}$. Therefore, the intense emerald green colour was achieved by the synergic effect of the $\mathrm{Cu}^{2+}$ ions, which progressively shift their absorption band from blue to green due to the presence of a high lead oxide content in the glass, and the yellow colour 


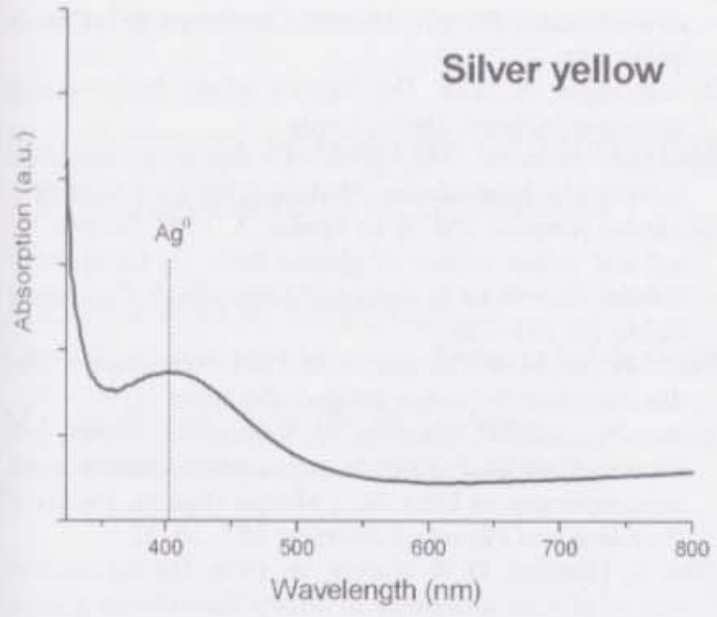

Figure 7. Visible absorption spectrum from a bulk silver yellow glass probably of the soda-lime-silicate type.

the optical absorption results, since the concentration of manganese oxide in this glass was $1.14 \mathrm{wt} \%$.

The bulk yellow colour is due to the formation of Ag silver colloidal nanoparticles, which are responsible of the absorption recorded at around $400 \mathrm{~nm}$ in the spectrum of Figure 7. The introduction of silver compounds in the glass gives rise to the formation of colloidal nanoparticles through the following three steps process: 1) dissolution of $\mathrm{Ag}^{+}$ions and incorporation into the glass network, 2) thermal reduction of $\mathrm{Ag}^{+}$ions to $\mathrm{Ag}$ atoms by means of a reducing atmosphere, and 3) precipitation and aggregation of $\mathrm{Ag}$ atoms which tend to form colloidal nanoparticles responsible of the yellow colouring (Fernández Navarro \& La Iglesia 1994). Due to the reduced number of bulk yellow glass fragments found and the low weight available, it was not possible to analyze them chemically by XRF. Consequently, the content of silver could not be analytically confirmed.

In any case, a very low concentration of silver (from 0.05 to $0.50 \mathrm{wt} \%$ ) is enough to provide the characteristic silver yellow colour to the glass (Fernández Navarro 2003: 472).

Finally, Figure 8 displays the absorption spectrum from a bulk red soda-lime-silicate glass. It shows an intense and well-defined absorption band at around $560 \mathrm{~nm}$, which is characteristic of copper ruby red glasses. The red colour is due to the formation of $\mathrm{Cu}^{+} / \mathrm{Cu}$ colloidal nanoparticles in a similar process to the silver ones but using copper compounds. The minimum concentration of copper oxide to produce the ruby red colour is estimated in $\sim 0.50 \mathrm{wt} \%$ (Fernández Navarro 2003: 468). The content of copper oxide determined in this sample by XRF was $0.59 \mathrm{wt} \%$.

Either in the case of copper or in the case of silver colloids it is necessary to produce critical reducing conditions during the glass melting to develop ruby red

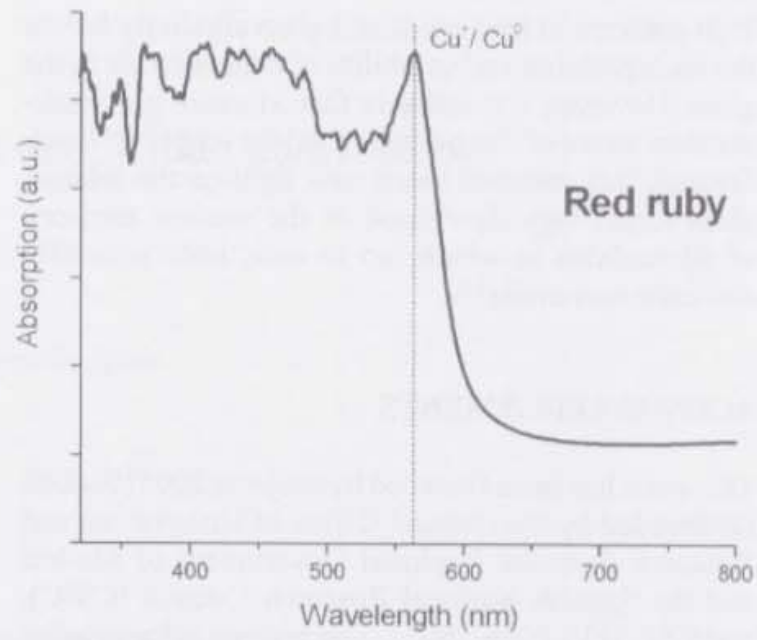

Figure 8. Visible absorption spectrum from a bulk ruby red soda-lime-silicate glass.

or yellow colouring. Therefore, from the technological point of view, obtaining such colours is difficult. It is important to point out that the solubility of both copper and silver nanoparticles rises as far as the alkalinity and the lead oxide concentration of the glass increase (Fernández Navarro 2003: 472). This fact could explain why a certain amount of lead oxide ( $2.84 \mathrm{wt} \%$ detected by XRF) was present in the bulk ruby red glass.

\section{CONCLUSIONS}

The results of the present research have allowed the assignment by UV/VIS absorption spectrophotometry of the ions responsible for each glass colouring studied. The characterization of these chromophores indicated that Murcian glassmakers of the 12 th century $\mathrm{AD}$ used copper oxide compounds to obtain emerald green, turquoise blue, green bluish and ruby red colouring in glasses. That is, by using the same copperbased chromophore, they were able to produce three different bulk colours varying the sensitive redox conditions of copper oxide during the melting process of glass. They also employed manganese oxide to obtain purple and some silver compounds to obtain the yellow colour. The presence of these ions was confirmed through chemical analysis by XRF, except in the case of the silver yellow in which there was not enough amount of sample available to be chemically analyzed.

The resulting data suggest, therefore, a deep knowledge of glass colouring techniques. This implies a high degree of specialization in glass production in which control over different colours and glass compositions was achieved. In this sense it is important to emphasize the use of a soda-lime lead-silicate glass to specifically produce the emerald green colour, since both 
high contents of lead oxide and glass alkalinity favour the incorporation and solubility of copper oxide to the glass. However, it is unlikely that Murcian glassmakers were aware of this point beyond the empirical level. Overall, this research sheds new light on the Islamic glass technology developed in the ancient territory of Al-Andalus in which, up to now, little scientific evidence was available.

\section{ACKNOWLEDGEMENTS}

This work has been financed by projects $200510 \mathrm{M} 068$ co-founded by the General Office of Universities and Research from the Regional Government of Madrid and the Spanish National Research Council (CSIC), and CSIC-PIE 200610I031. The authors acknowledge the General Office of Culture from the Regional Government of Murcia and the Archaeological Museum of this city for providing glass samples and for their useful collaboration. Dr. N. Carmona acknowledges an I3P (CSIC-ESF) postdoctoral contract. Finally, the authors are indebted to the CSIC Thematic Network on Cultural Heritage for its professional support.

\section{REFERENCES}

Bamford, C.R. 1977. Colour generation and control in glass. Amsterdam: Elsevier Science Publishers.

Carmona, N., Villegas, M.A., Jiménez Castillo, P., Navarro, J. \& Garcia-Heras, M. in press. Caracterización arqueométrica de vidrios andalusies procedentes de talleres murcianos. Actas de las Jornadas sobre Vidrio de la Alta Edad Media y Andalusi 2006. La Granja: Fundación Centro Nacional del Vidrio.

Castillo, F. \& Martinez, R. 2000. Un taller de vidrio en Bayyana-Pechina (Almeria). In P. Cressier (ed.), El vidrio en al-Andalus: 83-101. Madrid: Coeditions de la Casa de Velázquez.

De Gayangos, P. 1984. The History of the Mohammadan Dinasties in Spain. Delhi: 2 vols.

Fernández Navarro, J.M. 2003. El vidrio. Constitición. fabricación, propiedades. Madrid: CSIC (3rd edition).

Fernández Navarro, J.M. \& La Iglesia, A. 1994. Study of the red and yellow colour of glasses from the Cathedral of Toledo. Boletin de la Sociedad Española de Cerámicay Vidrio 33: 333-336.

Garcia-Heras, M. \& Villegas, M.A. 2004. Notas para el estudio cientifico del vidrio antiguo. Zephyrus 57: 377-390

Gómez-Paccard, M., Chauvin, A., Lanos, Ph., Thiriot, J.\& Jiménez Castillo, P. 2006. Archeomagnetic study of seven contemporaneous kilns from Murcia (Spain). Physics of the Earth and Planetary Interiors 157: 16-32.

Götz, J., Hoebbel, D. \& Wieker, W. 1976. On the constitution of silicate groupings in binary lead-silicate glasses Journal of Non-Crystalline Solids 22: 391-398.

Jiménez Castillo, P. 2000. El vidrio andalusi en Murcia In P. Cressier (ed.), El vidrio en al-Andalus: 117-148. Madrid: Coeditions de la Casa de Velázquez.

Jiménez Castillo, P. 2003. Murcia islámica. Una visión a través de la arqueologia. Murcia: Ayuntamiento de Murcia.

Jiménez Castillo, P., Muñoz, F. \& Thiriot, J. 2000. Les ateliets urbains de verriers de Murcia au XIlè siècle (c. Puxma. rina et pl. Belluga). In P. Pétrequin, P. Fluzin, J. Thiriot \& P. Benoit (eds.), Arts du feu et productions artisanales, XX Rencontres Internationales d'Archéologie et d'Histoire d'Antibes: 433-452. Antibes: Editions APDCA.

Jiménez Castillo, P., Navarro, J. \& Thiriot, J. 2005. Tallet de vidrio y casas andalusies en Murcia. La excavación arqueológica del casón de Puxmarina. Memorias de Arqueologia 13: 419 - 458.

Sanderson, D.C.W. \& Hutchings, J.B. 1987. The origin and measurement of colour in archaeological glasses. Glass Technology 28: 99-105.

Sayre, E.V. \& Smith, R.W. 1961. Compositional categories of ancient glass. Science 133; 1824-1826. 